
\title{
is Research Suare \\ Combined SuPAR and qSOFA for predicting 28-day mortality in sepsis
}

\author{
Lifeng Wang \\ Renji Hospital \\ Chao Tang \\ Renji Hospital \\ Shuangjun He \\ Renji Hospital \\ Yi Chen \\ Renji Hospital \\ Cuiying Xie ( $\nabla$ xiecuiyingrenji@163.com ) \\ Renji Hospital
}

\section{Research Article}

Keywords: Soluble urokinase-type plasminogen activator receptor, quick Sequential Organ Failure Assessment, combined model, sepsis, 28-day mortality

Posted Date: February 23rd, 2021

DOl: https://doi.org/10.21203/rs.3.rs-195966/v1

License: (c) (i) This work is licensed under a Creative Commons Attribution 4.0 International License.

Read Full License 


\section{Abstract \\ Background and Purpose}

To determine the prognostic performance of soluble urokinase-type plasminogen activator receptor (suPAR) and quick Sequential Organ Failure Assessment (qSOFA) in predicting the 28-day mortality of sepsis patients admitted to the emergency department (ED).

\section{Methods}

A prospective, single-center observational study was conducted between June 2018 and June 2019. In total, 175 patients with sepsis and septic shock admitted to the ED were enrolled based on the Third International Consensus Definitions for Sepsis and Septic Shock (Sepsis-3). We assessed the qSOFA score on ED admission and measured serum suPAR levels by quantitative enzyme-linked immunosorbent assay. Kaplan-Meier survival curves and areas under the receiver operating characteristic (ROC) curve for 28-day mortality were calculated. We estimated category-free net reclassification improvement (NRI) when suPAR was added to qSOFA.

\section{Results}

Increased suPAR levels were significantly associated with 28-day mortality $(1337(962-2003) \mathrm{pg} / \mathrm{ml}$ in survivors vs. $1742(1238-2514) \mathrm{pg} / \mathrm{ml}$ in non-survivors, $\mathrm{p}=0.011)$ and with sepsis severity $(1337(986-$ $1979)$ in sepsis vs. $1742(1215-2649)$ in septic shock, $p=0.039)$. Kaplan-Meier curves showed that suPAR $\geq 1382 \mathrm{pg} / \mathrm{mL}$ was associated with significantly higher 28-day mortality risk $(P=0.0028)$. The area under the curve (AUC) for the prediction of 28-day mortality was 0.646 for suPAR, 0.832 for qSOFA, and 0.860 for combined suPAR and qSOFA. Serum suPAR did not significantly increase the AUC of the basic qSOFA, but a model containing suPAR and qSOFA had a continuous NRI of $11 \%(95 \% \mathrm{Cl}: 3.5-18.5 \% ; \mathrm{p}=$ $0.004)$.

\section{Conclusion}

Serum suPAR is associated with sepsis severity and 28-day mortality. Adding suPAR to qSOFA may increase the ROC curve area and improve predictive value of qSOFA for outcome.

\section{Background}

Sepsis [1] is defined as a life-threatening organ dysfunction caused by a dysregulated host response to infection and is a common cause of morbidity and mortality worldwide. The annual incidence of sepsis has been estimated at approximately 31.5 million cases globally, with 5.3 million deaths per year [2]. The early identification of patients with adverse outcomes and aggressive treatment initiatives has decreased 
mortality in sepsis [3]. Therefore, the Third International Consensus Definitions for Sepsis and Septic Shock (Sepsis-3) focused on organ function and emphasized the incorporation of the Sequential Organ Failure Assessment (SOFA) score into the new definition of sepsis [4]. However, SOFA requires multiple laboratory tests and thereby increases the difficulty of detection in emergency department (ED) settings [5]. By contrast, the quick SOFA (qSOFA) provides simple bedside criteria to identify adult patients with suspected infection who are likely to have poor outcomes [1], especially in pre-ED settings. It does not require laboratory tests and can be assessed quickly and repeatedly. But in a recent editorial, qSOFA was described as an early warning system that cannot replace clinical evaluation [6] and has limited utility in early prognostication in high-mortality populations with sepsis. Used at the suggested cut-off $\geq 2$, qSOFA showed low sensitivity and high specificity [7].

Existing biomarkers fall short of the ideal accuracy for predicting sepsis mortality $[8,9]$. There is an urgent need to identify a simple, accurate, and effective biomarker to predict mortality in sepsis.

SuPAR is the soluble form of the cell membrane-bound urokinase plasminogen activator receptor (UPAR), which is expressed on various cell types, including neutrophils, lymphocytes, monocytes, endothelial cells, and tumor cells.

Donadello et al. [10] suggested that high levels of suPAR correlated with morbidity and outcome, supporting the value of suPAR as a prognostic biomarker in various cohorts of infected patients. A metaanalysis by Huang et al. [11] found that elevated suPAR levels are associated with a high risk of poor outcomes in sepsis. And studies have found that serum suPAR concentrations remained stable for days or weeks in critically ill patients $[12,13]$.

Although elevated suPAR levels in the initial stage of sepsis are associated with a high risk of death, the value of using suPAR alone to predict prognosis in sepsis is still limited. Hall et al. [14] suggested that it will also be important to compare the performance of suPAR with that of other biomarkers and to evaluate the role of suPAR in combination with existing severity of illness scores.

However, few studies have focused on the combination of sUPAR and qSOFA in predicting the mortality of sepsis patients in an emergency setting. The aim of this study was to determine the prognostic accuracy of suPAR combined with qSOFA in predicting the mortality of sepsis patients first admitted to the ED in China.

\section{Methods}

\section{Study population}

This prospective, observational study was conducted during the period of June 2018 through June 2019 among patients hospitalized in the ED of Renji Hospital (South Campus) affiliated to Shanghai Jiaotong University School of Medicine, a university tertiary hospital with approximately 120,000 ED visitors per year. 190 consecutive non-traumatic patients who fulfilled the Sepsis-3 criteria were enrolled in the study 
and eventual 175 patients included in the analysis and divided into non-survivors and survivors by 28-day mortality. The treatment and all methods were performed in accordance with the relevant guidelines and regulations of Sepsis 3.0.

The study was approved by the Ethics Committee of Renji Hospital Affiliated to Shanghai Jiaotong University School of Medicine (ethics NO.

:2016-109k), and all patients and legally authorized representative of deceased/non-survivor patients provided written informed consent for the study.

Sepsis was defined by the following criteria: infection + SOFA score $\geq 2$.

Septic shock should be clinically identified by a requirement for vasopressor to maintain a mean arterial pressure of $65 \mathrm{mmHg}$ or greater and serum lactate level greater than $2 \mathrm{mmol} / \mathrm{L}(>18 \mathrm{mg} / \mathrm{dL}$ ) in the absence of hypovolemia.

The clinical criteria of quick SOFA (qSOFA) were as follows : respiratory rate $\geq 22 / \mathrm{min}$, altered mentation, or systolic blood pressure $\leq 100 \mathrm{mmHg}$.

The exclusion criteria were age $<18$ years or the presence of any of the following: pregnancy, malignant tumor, or end-stage disease. We also excluded patients if they or their relatives declined participation in the study.

\section{Data collection}

Data including age, sex, underlying diseases, infection site, clinical data, severity of illness scores (including qSOFA, SOFA and Acute Physiology and Chronic Health Evaluation [APACHE] II scores), and laboratory data of all enrolled patients were recorded.

\section{Measurement of serum suPAR}

Peripheral venous blood samples were collected within $24 \mathrm{~h}$ of admission prior to intravenous antibiotics in sterile, pro-coagulation tubes and processed within $2 \mathrm{~h}$ after venipuncture. After standing for 30 minutes, they were centrifuged at $1914 \times \mathrm{g}$ for $10 \mathrm{~min}$ to separate the serum from the cellular components. The serum samples were stored at $-80^{\circ} \mathrm{C}$ for batch analysis[15].

Serum suPAR levels were measured using quantitative enzyme-linked immunosorbent assay (ELISA) kits (DUP00; R\&D Systems, Minneapolis, MN, USA) in duplicate as instructed by the manufacturer. The detection sensitivity was $33 \mathrm{pg} / \mathrm{mL}$, and the intra-assay and inter-assay coefficients of variation were < $8 \%$.

\section{Statistical analysis}

Continuous variables are expressed as median (interquartile range), and categorical variables are expressed as number (percentage). We used the Fisher's exact test to compare categorical variables and t-test or Mann-Whitney U test for continuous variables and abnormal distributional variables between 
two groups. Receiver operating characteristic (ROC) analysis was performed to compare survivors with non-survivors by Sigma Plot 14.0, and cut-off values were calculated according to Youden's index. Areas under the ROC curve (AUCs), optimal threshold values, sensitivity, and specificity were calculated, the sensitivities and specificities were further used to calculate the positive and negative likelihood ratios.

Kaplan-Meier methods were used to build 28-day survival curves; patients were stratified in two groups according to the cut-off calculated by Youden's Index.

Curves were compared by using the log-rank test. A two-sided $p$ value $<0.05$ was considered statistically significant; confidence intervals (Cls) were set at 95\%. To compare the qSOFA models with the suPAR and qSOFA models, the additive information on clinical variables was evaluated by the category-free net reclassification improvement (NRI) [16]. Statistical analyses were performed using the GraphPad Prism version 8.0 software (GraphPad Software, La Jolla, CA, USA) and R statistical software (Foundation for Statistical Computing, Vienna, Austria) version 3.4.0.

\section{Results}

\section{Demographic and clinical characteristics of total enrolled patients with sepsis}

From June 2018 to June 2019, 190 patients were screened for eligibility. Of these, 15 patients were excluded ( 1 patient was unable to contact a legal representative, 5 patients declined to participate, and 9 patients' blood samples were not available in a timely manner on admission). Finally, 175 patients were included in the analysis and divided into non-survivors and survivors (Table 1). 
Table 1

Characteristics of the total septic patients at baseline

\begin{tabular}{|c|c|c|c|}
\hline Characteristic & Total $(n=175)$ & Non-survivors $(n=41)$ & Survivors( $n=134)$ \\
\hline Age(years) median(IQR) & $66(53-77)$ & $69(53-81)$ & $66(53-75)$ \\
\hline Sex (male) n(\%) & $110(62.9)$ & $26(63.4)$ & $84(62.7)$ \\
\hline \multicolumn{4}{|l|}{ Underlying diseases n(\%) } \\
\hline Hypertension & $71(40.6)$ & $21(51.2)$ & $50(37.3)$ \\
\hline Diabetes mellitus & $51(29.1)$ & $8(19.5)$ & $43(32.1)$ \\
\hline Coronary heart disease & 33(18.9) & $17(41.5)$ & 16(11.9) \\
\hline Cerebral infarction & $35(20)$ & $10(24.4)$ & $25(18.7)$ \\
\hline Chronic pulmonary disease & 15(8.6) & $6(14.6)$ & $9(6.7)$ \\
\hline Autoimmune disease & $34(19.4)$ & 17(41.5) & $17(12.7)$ \\
\hline Surgical history & $36(20.6)$ & $9(22)$ & $27(21.1)$ \\
\hline \multicolumn{4}{|l|}{ Infection site n(\%) } \\
\hline Respiratory tract infection & $105(60)$ & $39(95.1)$ & $66(49.3)$ \\
\hline Urinary tract infection & $36(20.6)$ & $2(4.9)$ & $34(25.4)$ \\
\hline Gastrointestinal infection & 15(8.6) & $2(4.9)$ & 13(9.7) \\
\hline Hepatobiliary system infection & 18(10.3) & $1(2.4)$ & $17(12.7)$ \\
\hline Skin infection & $13(7.4)$ & $4(9.8)$ & $9(6.7)$ \\
\hline Intracranial infection & $5(2.9)$ & 0 & $5(3.7)$ \\
\hline Bloodstream infection & $41(23.4)$ & $5(12.2)$ & $36(26.9)$ \\
\hline Unknown origin & $10(5.7)$ & $1(2.4)$ & $9(6.7)$ \\
\hline \multicolumn{4}{|l|}{$\begin{array}{l}\text { Severity related variable } \\
\mathrm{n}(\%) \text { or median(IQR) }\end{array}$} \\
\hline Mechanical ventilation & $44(25.1)$ & $31(75.6)$ & 13(9.7) \\
\hline Vasopressor use & $53(30.3)$ & $35(85.4)$ & 18(13.4) \\
\hline CRRT & $11(6.3)$ & $5(12.2)$ & $6(4.5)$ \\
\hline qSOFA & $1(0-2)$ & $3(1.5-3)$ & $1(0-1)$ \\
\hline SOFA & $4(2-8)$ & $10(7-14)$ & $3(2-6)$ \\
\hline APACHE II & $14(9-24)$ & $29(21-31.5)$ & $12(8-18)$ \\
\hline
\end{tabular}




\begin{tabular}{|llll|}
\hline Characteristic & Total $(\mathbf{n}=\mathbf{1 7 5})$ & Non-survivors $(\mathbf{n}=\mathbf{4 1})$ & Survivors $(\mathbf{n}=\mathbf{1 3 4})$ \\
\hline Septic shock & $49(28)$ & $35(85.4)$ & $14(10.4)$ \\
\hline Clinical variable median $(\mathrm{IQR})$ & & & \\
\hline $\mathrm{WBC}\left(\times 10^{9} / \mathrm{L}\right)$ & $10.12(6.70-13.40)$ & $12.05(7.19-14.60)$ & $9.56(6.48-13.14)$ \\
\hline $\mathrm{Hb}(\mathrm{g} / \mathrm{L})$ & $123(107-137)$ & $119(95-133)$ & $125(108-137)$ \\
\hline $\mathrm{Plt}\left(\times 10^{9} / \mathrm{L}\right)$ & $161(99-217)$ & $155(64-215)$ & $166(107-217)$ \\
\hline $\mathrm{CRP}(\mathrm{mg} / \mathrm{L})$ & $123(39-200)$ & $118(43-190)$ & $125(33-200)$ \\
\hline $\mathrm{PCT}(\mathrm{ng} / \mathrm{ml})$ & $1.94(0.46-11.33)$ & $1.75(0.46-7.77)$ & $2.07(0.45-12.21)$ \\
\hline Lactate $(\mathrm{mmol} / \mathrm{L})$ & $2.39(1.60-3.48)$ & $2.80(2.10-4.50)$ & $2.20(1.50-3.12)$ \\
\hline Creatinine(umol/L) & $91(64-139)$ & $109(60-175)$ & $86(64-126)$ \\
\hline suPAR $(\mathrm{pg} / \mathrm{ml})$ & $1449(1051-2206)$ & $1742(1238-2514)$ & $1337(962-2003)$ \\
\hline Outcome variable $\mathrm{n}(\%)$ & & & \\
\hline 28-day mortality & $41(23.4)$ & & \\
\hline
\end{tabular}

The analysis included 134 survivors and 41 non-survivors. The non-survivors group had a more proportion of coronary heart disease ( $41.5 \%$ vs. $11.9 \%)$, autoimmune disease $(41.5 \%$ vs. $12.7 \%)$ and respiratory tract infection( $95.1 \%$ vs. $49.3 \%)$.In addition, non-survivors were more likely to be on mechanical ventilation (75.6\% vs.9.7\%), vasopressor use( $85.4 \%$ vs. $13.4 \%$ ), and CRRT( $12.2 \%$ vs. $4.5 \%)$ compared with survivors. Furthermore, non-survivors had higher qSOFA, SOFA ,and APACHII score, as well as high lactate levels and suPAR compared with survivors. (3 vs. 1), SOFA score (10 vs. 3), APACHE II score (29 vs. 12), lactate (2.80 vs. $2.20 \mathrm{mmol} / \mathrm{L})$, and higher suPAR(1742 [1238-2514] vs. 1337 [9622003]pg/mL) compared with survivors. And the total 28-day mortality was $23.4 \%$ (41/175).

\section{Serum suPAR level in sepsis and septic shock groups vs. survivor and non-survivor groups}

Comparison of suPAR in patients with sepsis and septic shock, survivors and non-survivors is shown in Fig. 1. Serum suPAR levels were significantly higher in the septic shock and non-survivor groups than in the sepsis and survivor groups (1742(1215-2649) pg/mL and 1742(1238-2514) pg/mL vs.(1337(9861979) $\mathrm{pg} / \mathrm{mL}$ and (1337(962-2003) $\mathrm{pg} / \mathrm{mL}, \mathrm{p}=0.0039$ and $\mathrm{p}=0.011$, respectively).

\section{Value of suPAR in predicting 28-day mortality in patients with sepsis}

In this study, Kaplan-Meier curves were used to assess the value of suPAR in the prediction of 28-day mortality in patients with sepsis (Fig. 2). The 28-day mortality in high cut-off of suPAR categories ( $\geq$ 
$1382 \mathrm{pg} / \mathrm{mL}$ ) was significantly higher than in low cut-off of suPAR categories $(<1382 \mathrm{pg} / \mathrm{mL}$ ) (log-rank, $p$ $=0.0028)$.

\section{Prognostic value of combination suPAR and qSOFA in predicting 28-day mortality in sepsis patients}

Table 2 and Fig. 3 shows the ROC analysis for the combination of suPAR and qSOFA and qSOFA alone in predicting the 28-day mortality in sepsis patients. AUCs of various parameters for predicting 28-day mortality in patients with sepsis based on Sepsis-3 are shown in Table 2. The AUC of using a combination of suPAR and qSOFA $(0.860)$ was better than that of using qSOFA (0.832) or SuPAR $(0.646)$ alone, and also better than those of using suPAR combined with CRP $(0.654)$ or PCT $(0.653)$, The differences were statistically significant among suPAR + qSOFA compared with suPAR,suPAR + CRP and suPAR + PCT, (Pख0.001》respectively) but not statistically significant compared with qSOFA $(p=0.082)$. A model containing suPAR in addition to qSOFA had a continuous NRI of $11 \%(95 \% \mathrm{Cl}: 3.5-18.5 \% ; p=$ 0.004) (data were not shown). And there was no significant difference between AUC of combined or single model with CHD and without CHD ( $P=0.447$, data was not shown), on account of that suPAR is independently associated with the presence and severity of heart failure.

Table 2

Results of the ROC analysis of various variables for predicting 28-d mortality of sepsis

\begin{tabular}{|c|c|c|c|c|c|c|c|c|}
\hline Variable & AUC $(95 \% \mathrm{Cl})$ & $\begin{array}{l}P \\
\text { value* }\end{array}$ & $\begin{array}{l}\text { Cut- } \\
\text { off }(\geq)\end{array}$ & $\begin{array}{l}\text { Youden's } \\
\text { index }\end{array}$ & Sens. & Spec. & LR+ & LR- \\
\hline $\begin{array}{l}\text { suPAR } \\
(\mathrm{pg} / \mathrm{ml})\end{array}$ & $\begin{array}{l}0.646(0.552- \\
0.741)\end{array}$ & $\otimes 0.001$ & 1382 & 0.261 & 0.732 & 0.53 & 0.322 & 0.777 \\
\hline qSOFA & $\begin{array}{l}0.832(0.692- \\
0.923)\end{array}$ & 0.082 & 1.5 & 0.517 & 0.756 & 0.761 & 0.491 & 0.909 \\
\hline $\begin{array}{l}\text { suPAR + } \\
\text { qSOFA }\end{array}$ & $\begin{array}{l}0.860(0.795- \\
0.914)\end{array}$ & & 0.335 & 0.627 & 0.732 & 0.895 & 0.680 & 0.916 \\
\hline $\begin{array}{l}\text { SuPAR + } \\
\text { CRP }\end{array}$ & $\begin{array}{l}0.654(0.561- \\
0.740)\end{array}$ & $₫ 0.001$ & 0.223 & 0.276 & 0.634 & 0.642 & 0.351 & 0.852 \\
\hline $\begin{array}{l}\text { suPAR + } \\
\text { PCT }\end{array}$ & $\begin{array}{l}0.653(0.548- \\
0.745)\end{array}$ & $\varangle 0.001$ & 0.211 & 0.323 & 0.756 & 0.567 & 0.348 & 0.884 \\
\hline
\end{tabular}

\section{Discussion}

This paper is the first to investigate suPAR levels combined with the qSOFA score in patients with sepsis based on Sepsis-3. We developed a simple risk stratification system for patients with sepsis by taking into consideration qSOFA score and the serum biomarker suPAR . 
In the current study, we found that suPAR performed better predictive value for 28-day hospital mortality of patients with sepsis or septic shock than commonly used biomarkers, such as CRP and PCT. Moreover, the predictive abilities were slightly improved when suPAR combined with qSOFA scores.

Sepsis is a physiopathological process rather than a specific syndrome[17], and it is too complex and cannot be simply described by a single measure. For this reason, neither clinical nor biological markers have been demonstrated to be perfect prognostic tools. Severity scores such as the Acute Physiology and Chronic Health Evaluation (APACHE) II score and Sequential Organ Failure Assessment (SOFA) score are the gold standard for severity assessment of critically ill patients [18]. However, the assessment of scoring systems to guide decision making in sepsis is sophisticated and is not readily available in pre-ED.

Recently, some authors reported that qSOFA could be a useful tool in hospital ED settings outside the intensive care unit. In this case, qSOFA could predict death of sepsis patients, but it could be overcome by rapid and accurate laboratory diagnostic tests [19]. qSOFA score with a cut-off value of $\geq 2$ showed a low sensitivity and high specificity. Our study found that the AUC of qSOFA alone was 0.832 for 28 -day mortality. Furthermore, the present study showed that qSOFA alone has a low post-test probability that increased significantly when associated with PCT [7]. In the analysis by Giamarellos-Bourboulis et al [20], qSOFA score had inadequate sensitivity for early risk assessment.

Classical biomarkers have not been shown to be better than generic scores in predicting outcome in septic patients [21]. Many studies focus on the prognostic value of suPAR which has been proposed as a biomarker for the risk of death. Early increase in suPAR has also been reported to be strongly associated with risk of in-hospital-, 30-day-, and 90-day mortality in sepsis patients and correlated with sepsis severity [22-24]. In our study, we found that serum suPAR levels were significantly higher in the septic shock and non-survivor groups than in the sepsis and survivor groups. Our results are consistent with those of previous studies. The AUC for suPAR in predicting in-hospital mortality ranges from 0.67 to 0.84 $[17,23,25,26]$. Several studies have showed the superiority of suPAR over conventional biomarkers such as CRP and PCT [13, 25, 27-29]. Consistent with previous reports, the AUC for suPAR of out study to predict mortality was 0.646 which was also better than CRP and PCT(0.483 vs 0.470$)$.

Kaplan-Meier curves showed that suPAR $\geq 1382 \mathrm{pg} / \mathrm{mL}$ was associated with significantly higher 28-day mortality risk; this threshold value is identical to that reported in prior studies $[17,30]$.

Based on the above analysis, we indicate that suPAR may provide a promising prognostic biomarker in sepsis.

There were several studies of suPAR combined with other indicators or qSOFA combined with other indicators in prediction of mortality of infected patients. Kofoed et al. [31] demonstrated that suPAR levels had a better prognostic value than PCT and CRP, equal to that of the admission SOFA score and almost as good as that of the Simplified Acute Physiology Score( SAPS ) II score and that the combination of suPAR and age had a better prognostic value than the SAPS II score alone. JuliánJiménez et al found that qSOFA scores achieved better results for 30-day mortality than systemic 
inflammatory response syndrome, and that qSOFA plus mid regional pro-adrenomedullin [MR-proADM] could increase the predictive power in elderly patients visit ED due to infections than qSOFA alone[32].

There has been no report on the prognostic value of combining suPAR and qSOFA. We propose to improve prognostication of 28-day mortality of sepsis by using the qSOFA score combined with suPAR, a serum biomarker that is easily performed on-site and provides information within $1 \mathrm{~h}$ [33]. Our results show that the AUC of the combination of suPAR and qSOFA was better than that of qSOFA or suPAR alone and combined model(suPAR + CRP and suPAR + PCT).

There is a fact that suPAR is a non-specific inflammatory marker and a strong and independent predictor of mortality in patients with CHF[34], Data presented in Tabel 1 showed that non-survivors compared with survivors included more patients with coronary heart disease (41.5\% vs. $11.9 \%)$. So we assessed the ROC of the combined model and single model that was no significant difference between two groups stratified by $\mathrm{CHD}$ and without $\mathrm{CHD}(\mathrm{P}=0.447$, data was not shown).

There were some limitations of ROC curves in evaluating biomarkers [35]. Thus, the net reclassification improvement (NRI) was applied to estimate the strength of associations in this study.The NRI captures the relative improvement in classification associated with the additional predictive variable, while explicitly balancing trade off between changes in sensitivity and specificity. NRI is the sum of 2 percentages with different denominators and hence, is reported as a proportion (possible range, -2.0 to 2.0)[36].Although serum suPAR did not significantly increase the AUC of the basic qSOFA, a model containing suPAR in addition to qSOFA had a continuous NRI of $11 \%(95 \% \mathrm{Cl}: 3.5-18.5 \%, p=0.004)$. In other words, the addition of suPAR to the clinical predictive model (qSOFA) could improve its discrimination and predictive value for outcomes than qSOFA alone.

\section{Limitations}

Our study has substantial limitations. First, serum suPAR levels were only detected at the time of admission; dynamic and follow-up changes (in response to treatment) were not investigated. Second, several comorbidities (e.g., diabetes mellitus[37], $\mathrm{CHD}$ [34]) may also influence the suPAR values, however this reflected a real world setting and we did a subgroup analysis according to the presence or absence of CHD. Finally, we did not examine the suPAR levels of healthy controls for comparison owing to limitations of funding and ethical considerations. Hence, the effects of changes in suPAR expression during the pathogenesis of sepsis should be investigated in future studies with a larger sample size. Further research is required to evaluate the predictive efficacy of suPAR in combination with other indicators.

\section{Conclusions}

We demonstrated that serum suPAR levels were associated with sepsis severity and 28-day mortality in patients with sepsis. The addition of suPAR to the clinical model (qSOFA) may increased the ROC curve area and improve predictive value of qSOFA for outcome. 


\section{Abbreviations}

suPAR, soluble urokinase-type plasminogen activator receptor; qSOFA, quick Sequential Organ Failure Assessment; SOFA, Sequential Organ Failure Assessment; ED, emergency department; NRI, net reclassification improvement; BNP, B-type natriuretic peptide; CRP, C-reactive protein; $\mathrm{PCT}$, procalcitonin; WBC, Whole blood leukocyte count; OR, odds ratio; $\mathrm{Cl}$, confidence interval; IQR, Interquartile range; Sepsis3, Third International Consensus Definitions for Sepsis and Septic Shock; APACHE, Acute Physiology and Chronic Health Evaluation; SAPS, Simplified Acute Physiology Score; MR-proADM, Mid regional proadrenomedullin; $\mathrm{CHD}$, coronary heart disease; $\mathrm{CHF}$, congestive heart failure

\section{Declarations}

Ethics approval and consent to participate $\$ The study was approved by the Ethics Committee of Renji Hospital Affiliated to Shanghai Jiaotong University School of Medicine (ethics N0.:2016-109k) and the 1964 Helsinki declaration and its later amendments or comparable ethical standards, and all patients and legally authorized representative of deceased/non-survivor patients provided written informed consent for the study.

Consent for publication $₫$ Not applicable.

Availability of data and materials $₫$ The datasets used and/or analysed during the current study available from the corresponding author on reasonable request.

Competing interests: All of the authors have no competing interests.

Funding: Not applicable.

Authors' contributions: LW and CT contributed equally to the writing of this manuscript. SH and YC participated in data interpretation and statistical analysis. CX revised the whole manuscript. All authors read and approved the final manuscript.

Acknowledgements: The authors thank professor Shuang Ye and Dr. Chenyu Fan for their excellent assistance with study coordination and laboratory analyses.

\section{References}

1. Seymour CW, Liu VX, Iwashyna TJ, Brunkhorst FM, Rea TD, Scherag A, Rubenfeld G, Kahn JM, Shankar-Hari M, Singer M et al: Assessment of Clinical Criteria for Sepsis: For the Third International Consensus Definitions for Sepsis and Septic Shock (Sepsis-3). JAMA 2016, 315(8):762-774.

2. Fleischmann C, Scherag A, Adhikari NK, Hartog CS, Tsaganos T, Schlattmann P, Angus DC, Reinhart $\mathrm{K}$ : Assessment of Global Incidence and Mortality of Hospital-treated Sepsis. Current Estimates and Limitations. Am J Respir Crit Care Med 2016, 193(3):259-272.

3. Kaukonen KM, Bailey M, Suzuki S, Pilcher D, Bellomo R: Mortality related to severe sepsis and septic shock among critically ill patients in Australia and New Zealand, 2000-2012. Jama 2014, 
311(13):1308-1316.

4. Shankar-Hari M, Phillips GS, Levy ML, Seymour CW, Liu VX, Deutschman CS, Angus DC, Rubenfeld GD, Singer M: Developing a New Definition and Assessing New Clinical Criteria for Septic Shock: For the Third International Consensus Definitions for Sepsis and Septic Shock (Sepsis-3). Jama 2016, 315(8):775-787.

5. Singer M, Deutschman CS, Seymour CW, Shankar-Hari M, Annane D, Bauer M, Bellomo R, Bernard GR, Chiche JD, Coopersmith CM et al: The Third International Consensus Definitions for Sepsis and Septic Shock (Sepsis-3). Jama 2016, 315(8):801-810.

6. Vincent JL, Martin GS, Levy MM: qSOFA does not replace SIRS in the definition of sepsis. Crit Care 2016, 20(1):210.

7. Spoto S, Cella E, de Cesaris M, Locorriere L, Mazzaroppi S, Nobile E, Lanotte AM, Pedicino L, Fogolari M, Costantino S et al: Procalcitonin and MR-Proadrenomedullin Combination with SOFA and qSOFA Scores for Sepsis Diagnosis and Prognosis: A Diagnostic Algorithm. Shock (Augusta, Ga) 2018, 50(1):44-52.

8. Andriolo BN, Andriolo RB, Salomão R, Atallah Á N: Effectiveness and safety of procalcitonin evaluation for reducing mortality in adults with sepsis, severe sepsis or septic shock. The Cochrane database of systematic reviews 2017, 1(1):Cd010959.

9. Rivers EP, Jaehne AK, Nguyen HB, Papamatheakis DG, Singer D, Yang JJ, Brown S, Klausner H: Early biomarker activity in severe sepsis and septic shock and a contemporary review of immunotherapy trials: not a time to give up, but to give it earlier. Shock (Augusta, Ga) 2013, 39(2):127-137.

10. Donadello K, Scolletta S, Covajes C, Vincent JL: suPAR as a prognostic biomarker in sepsis. BMC Med 2012, 10:2.

11. Huang Q, Xiong H, Yan P, Shuai T, Liu J, Zhu L, Lu J, Yang K, Liu J: The Diagnostic and Prognostic Value of suPAR in Patients with Sepsis: A Systematic Review and Meta-Analysis. Shock 2020, 53(4):416-425.

12. Giamarellos-Bourboulis EJ, Norrby-Teglund A, Mylona V, Savva A, Tsangaris I, Dimopoulou I, Mouktaroudi M, Raftogiannis M, Georgitsi M, Linnér A et al: Risk assessment in sepsis: a new prognostication rule by APACHE II score and serum soluble urokinase plasminogen activator receptor. Crit Care 2012, 16(4):R149.

13. Koch A, Voigt S, Kruschinski C, Sanson E, Dückers H, Horn A, Yagmur E, Zimmermann H, Trautwein C, Tacke F: Circulating soluble urokinase plasminogen activator receptor is stably elevated during the first week of treatment in the intensive care unit and predicts mortality in critically ill patients. Crit Care 2011, 15(1):R63.

14. Hall A, Crichton S, Varrier M, Bear DE, Ostermann M: suPAR as a marker of infection in acute kidney injury - a prospective observational study. BMC Nephro/2018, 19(1):191.

15. Wang L, Zhou W, Wang K, He S, Chen Y: Predictive value of circulating plasma mitochondrial DNA for Sepsis in the emergency department: observational study based on the Sepsis-3 definition. BMC emergency medicine 2020, 20(1):25. 
16. Cook NR, Paynter NP: Performance of reclassification statistics in comparing risk prediction models. Biometrical journal Biometrische Zeitschrift 2011, 53(2):237-258.

17. Suberviola B, Castellanos-Ortega A, Ruiz Ruiz A, Lopez-Hoyos M, Santibanez M: Hospital mortality prognostication in sepsis using the new biomarkers suPAR and proADM in a single determination on ICU admission. Intensive Care Med 2013, 39(11):1945-1952.

18. Knaus WA, Draper EA, Wagner DP, Zimmerman JE: APACHE Il: a severity of disease classification system. Crit Care Med 1985, 13(10):818-829.

19. Lamontagne F, Harrison DA, Rowan KM: qSOFA for Identifying Sepsis Among Patients With Infection. Jama 2017, 317(3):267-268.

20. Giamarellos-Bourboulis EJ, Tsaganos T, Tsangaris I, Lada M, Routsi C, Sinapidis D, Koupetori M, Bristianou M, Adamis G, Mandragos K et al: Validation of the new Sepsis-3 definitions: proposal for improvement in early risk identification. Clinical microbiology and infection: the official publication of the European Society of Clinical Microbiology and Infectious Diseases 2017, 23(2):104-109.

21. Antonelli M, Azoulay E, Bonten M, Chastre J, Citerio G, Conti G, De Backer D, Lemaire F, Gerlach H, Hedenstierna $G$ et al: Year in review in Intensive Care Medicine 2009: I. Pneumonia and infections, sepsis, outcome, acute renal failure and acid base, nutrition and glycaemic control. Intensive Care Med 2010, 36(2):196-209.

22. Giamarellos-Bourboulis EJ, Norrby-Teglund A, Mylona V, Savva A, Tsangaris I, Dimopoulou I, Mouktaroudi M, Raftogiannis M, Georgitsi M, Linner A et al: Risk assessment in sepsis: a new prognostication rule by APACHE II score and serum soluble urokinase plasminogen activator receptor. Crit Care 2012, 16(4):R149.

23. Huttunen R, Syrjänen J, Vuento R, Hurme M, Huhtala H, Laine J, Pessi T, Aittoniemi J: Plasma level of soluble urokinase-type plasminogen activator receptor as a predictor of disease severity and case fatality in patients with bacteraemia: a prospective cohort study. J Intern Med 2011, 270(1):32-40.

24. Rasmussen LJH, Ladelund S, Haupt TH, Ellekilde GE, Eugen-Olsen J, Andersen O: Combining National Early Warning Score With Soluble Urokinase Plasminogen Activator Receptor (suPAR) Improves Risk Prediction in Acute Medical Patients: A Registry-Based Cohort Study. Critical care medicine 2018, 46(12):1961-1968.

25. Mölkänen T, Ruotsalainen E, Thorball CW, Järvinen A: Elevated soluble urokinase plasminogen activator receptor (suPAR) predicts mortality in Staphylococcus aureus bacteremia. European journal of clinical microbiology \& infectious diseases: official publication of the European Society of Clinical Microbiology 2011, 30(11):1417-1424.

26. Luo Q, Ning P, Zheng Y, Shang Y, Zhou B, Gao Z: Serum suPAR and syndecan-4 levels predict severity of community-acquired pneumonia: a prospective, multi-centre study. Crit Care 2018, 22(1):15.

27. Yilmaz G, Köksal I, Karahan SC, Mentese A: The diagnostic and prognostic significance of soluble urokinase plasminogen activator receptor in systemic inflammatory response syndrome. Clinical biochemistry 2011, 44(14-15):1227-1230. 
28. Wittenhagen P, Kronborg G, Weis N, Nielsen H, Obel N, Pedersen SS, Eugen-Olsen J: The plasma level of soluble urokinase receptor is elevated in patients with Streptococcus pneumoniae bacteraemia and predicts mortality. Clinical microbiology and infection: the official publication of the European Society of Clinical Microbiology and Infectious Diseases 2004, 10(5):409-415.

29. Savva A, Raftogiannis M, Baziaka F, Routsi C, Antonopoulou A, Koutoukas P, Tsaganos T, Kotanidou A, Apostolidou E, Giamarellos-Bourboulis EJ et al: Soluble urokinase plasminogen activator receptor (suPAR) for assessment of disease severity in ventilator-associated pneumonia and sepsis. $J$ Infect 2011, 63(5):344-350.

30. Jalkanen V, Yang R, Linko R, Huhtala H, Okkonen M, Varpula T, Pettila V, Tenhunen J, Group FS:

SuPAR and PAl-1 in critically ill, mechanically ventilated patients. Intensive Care Med 2013, 39(3):489-496.

31. Kofoed K, Eugen-Olsen J, Petersen J, Larsen K, Andersen O: Predicting mortality in patients with systemic inflammatory response syndrome: an evaluation of two prognostic models, two soluble receptors, and a macrophage migration inhibitory factor. European journal of clinical microbiology \& infectious diseases: official publication of the European Society of Clinical Microbiology 2008, 27(5):375-383.

32. Julián-Jiménez A, Yañez MC, González-Del Castillo J, Salido-Mota M, Mora-Ordoñez B, Arranz-Nieto MJ, Chanovas-Borras MR, Llopis-Roca F, Mòdol-Deltell JM, Muñoz G: Prognostic power of biomarkers for short-term mortality in the elderly patients seen in Emergency Departments due to infections. Enfermedades infecciosas y microbiologia clinica 2019, 37(1):11-18.

33. Kofoed K, Schneider UV, Scheel T, Andersen O, Eugen-Olsen J: Development and validation of a multiplex add-on assay for sepsis biomarkers using xMAP technology. Clinical chemistry 2006, 52(7):1284-1293.

34. Koller L, Stojkovic S, Richter B, Sulzgruber P, Potolidis C, Liebhart F, Mörtl D, Berger R, Goliasch G, Wojta $\mathrm{J}$ et al: Soluble Urokinase-Type Plasminogen Activator Receptor Improves Risk Prediction in Patients With Chronic Heart Failure. JACC Heart failure 2017, 5(4):268-277.

35. Cook NR: Methods for evaluating novel biomarkers - a new paradigm. International journal of clinical practice 2010, 64(13):1723-1727.

36. Yeboah J, McClelland RL, Polonsky TS, Burke GL, Sibley CT, O'Leary D, Carr JJ, Goff DC, Greenland P, Herrington DM: Comparison of novel risk markers for improvement in cardiovascular risk assessment in intermediate-risk individuals. Jama 2012, 308(8):788-795.

37. Theilade S, Lyngbaek S, Hansen TW, Eugen-Olsen J, Fenger M, Rossing P, Jeppesen JL: Soluble urokinase plasminogen activator receptor levels are elevated and associated with complications in patients with type 1 diabetes. J Intern Med 2015, 277(3):362-371.

\section{Figures}




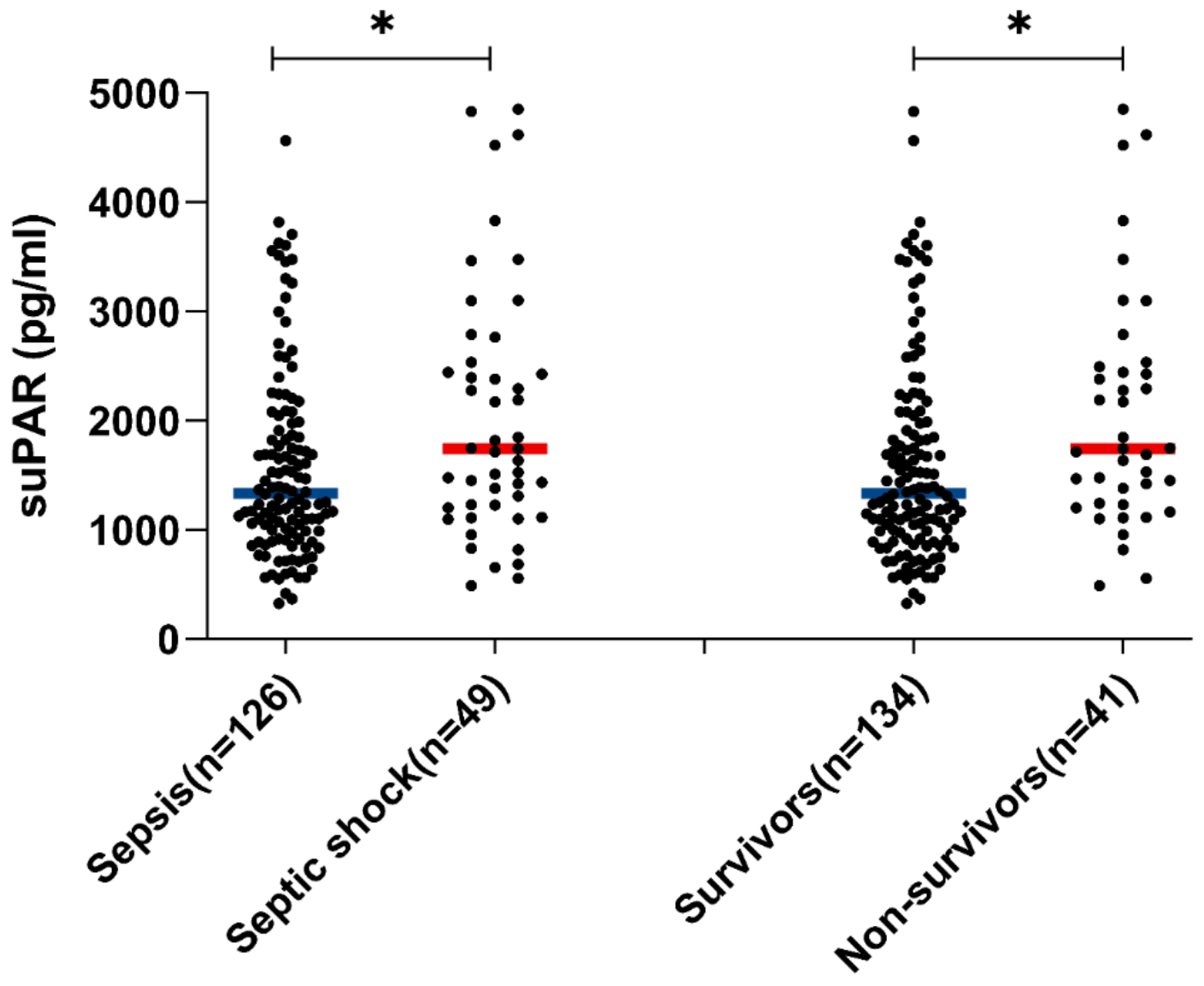

Figure 1

Comparison of suPAR in patients with sepsis and septic shock, with survivors and non-survivors. 


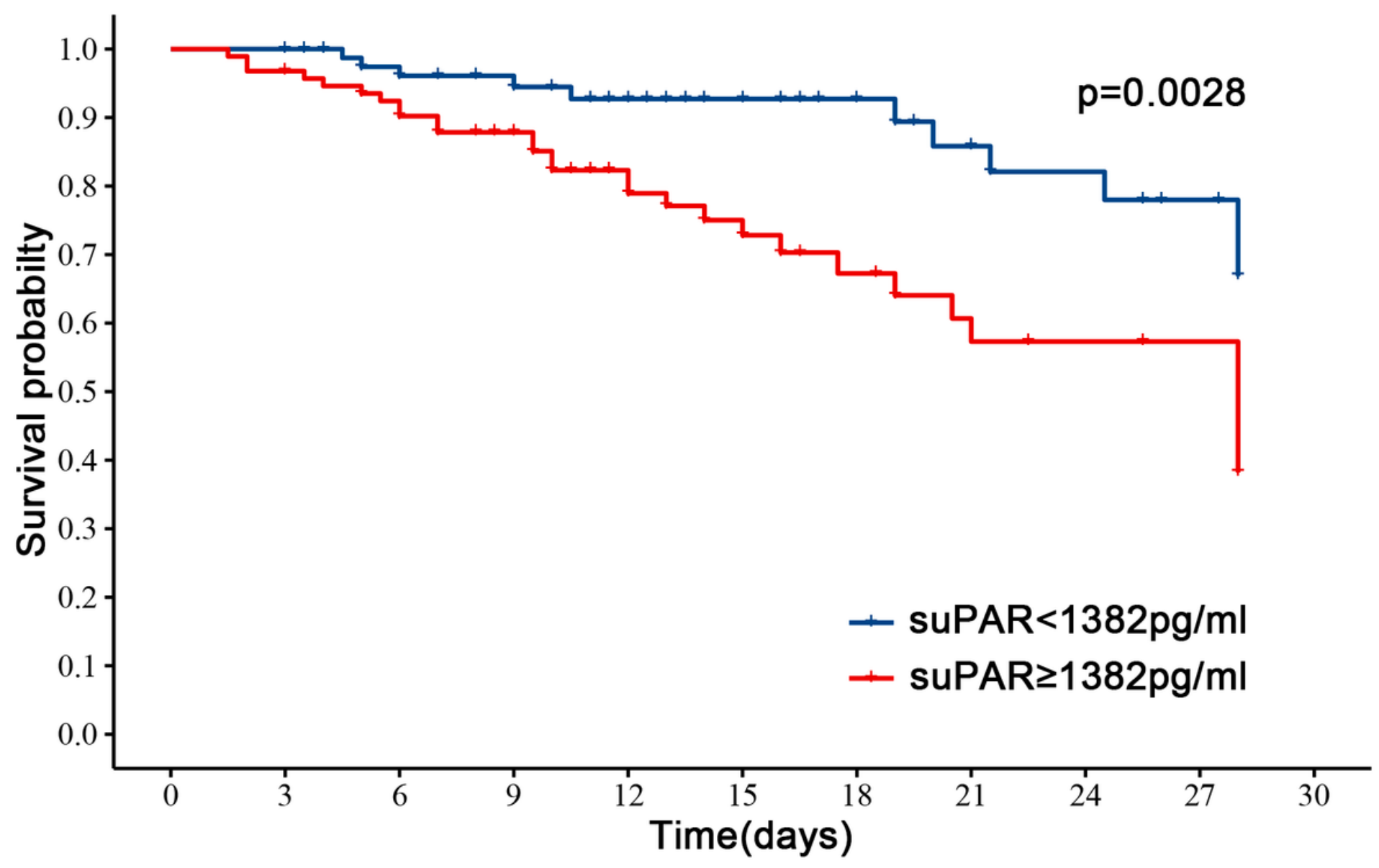

Figure 2

Kaplane Meier survival curves for 28-day cumulative survival. Patients were stratified in two groups according to the cut-off calculated by Youden's Index. Curves were compared by using the log-rank test 


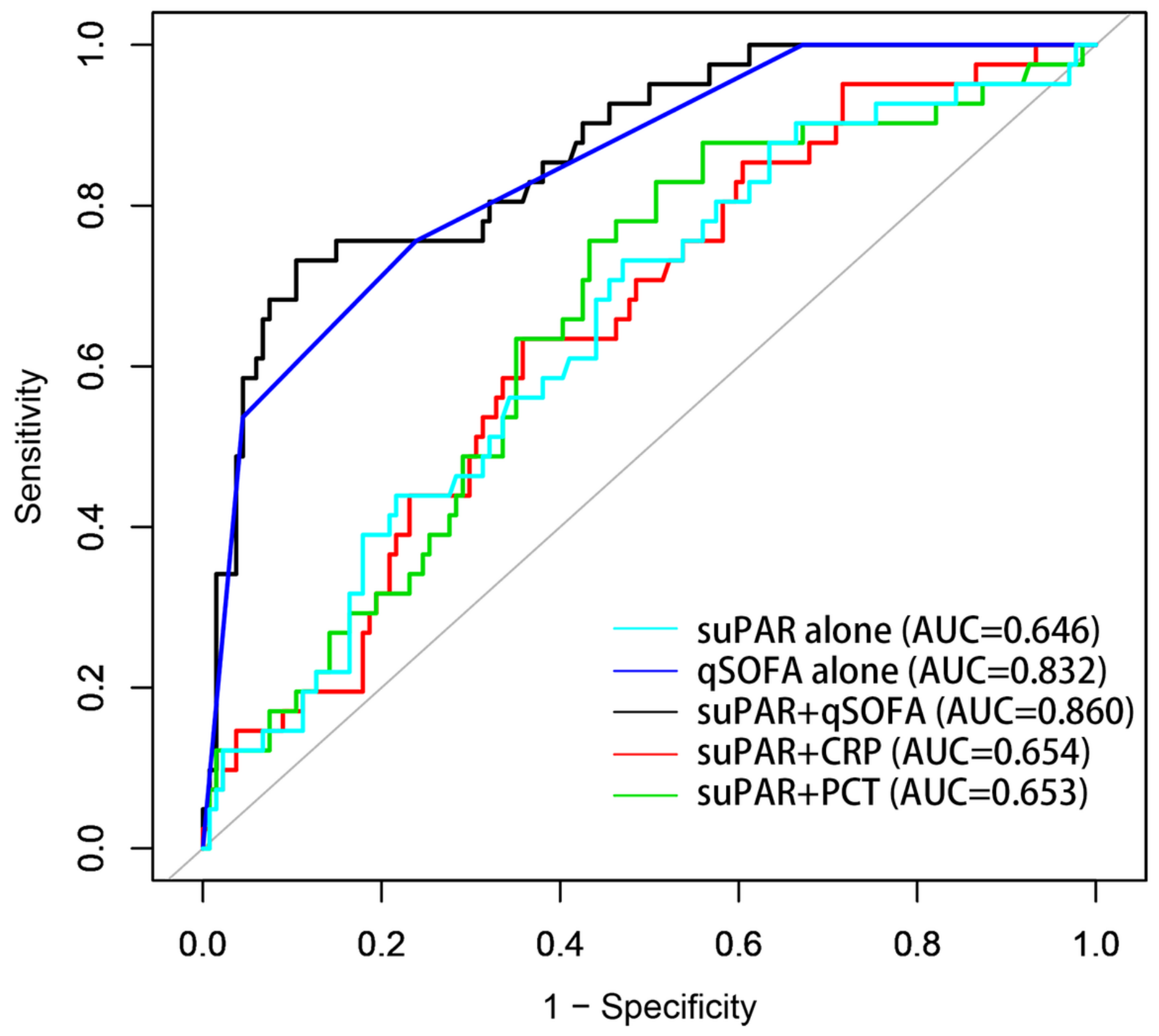

Figure 3

ROC analysis for predicting 28-day mortality in sepsis-3 patients 